\title{
RENCANA PENGELOLAAN OBJEK WISATA PANTAI BARON UNTUK MENINGKATKAN DAYA TARIK PENGUNJUNG (OBJEK STUDI : OBJEK WISATA PANTAI BARON DESA KEMADANG, KABUPATEN GUNUNGKIDUL)
}

\author{
Fitria Agistya Ningrum ${ }^{1)}$, B. Irwan Wipranata2), Sylvie Wirawati ${ }^{3)}$
}

\author{
${ }^{1)}$ Program Studi S1 PWK, Fakultas Teknik, Universitas Tarumanagara, Fitriagistya04@gmial.com \\ 2) Program Studi S1 PWK, Fakultas Teknik, Universitas Tarumanagara, irwan_wipranata@yahoo.co.uk \\ 3)Program Studi S1 PWK, Fakultas Teknik, Universitas Tarumanagara, Sylview@ft.untar.ac.id
}

Masuk: 30-07-2021, revisi: 03-09-2021, diterima untuk diterbitkan: 23-10-2021

\begin{abstract}
Abstrak
Pemerintahan berencana untuk menciptakan kondisi kawasan wisata yang ideal supaya mampu melayani berbagai kepentingan masyarakat, pengunjung pemerintah dalam usaha penataan dan pengembangan secara optimal dengan proses perencanaan yang matang, terarah dan terpadu sehingga dapat menjadi acuan dalam pengembangan pariwisata. Salah satu Daerah yang terpilih untuk dikembangkan yaitu Kabupaten GunungKidul, Menurut Peraturan Daerah Kabupaten GunungKidul Tentang RPJMD Tahun 2011-2021, Kabupaten GunungKidul memiliki beberapa potensi kawasan wisata yaitu pariwisata Pantai Baron. Tujuan penulis membuat laporan ini untuk Mengetahui bagaimana kondisi kawasan objek wisata baik fisik kawasan, sarana maupun prasarana dan Memberikan strategi pengelolaan terhadap kawasan wisata Pantai Baron agar menjadi wisata yang berkelanjutan. Pantai Baron adalah pantai yang dikembangkan pertamakali oleh pemerintah Kabupaten GunungKidul dengan luas 1,5 Ha, pantai baron dikenal dengan pantai yang memiliki TPI yang besar dan memiliki mercusuar tertinggi sehingga pengunjung dapat menikmati keindahan pantai tersebrut. Pantai ini juga menjadi tujuan utama wisata pantai jika berkunjung ke Kabupaten GunungKidul. Penelitian ini merupakan penelitian deskriptif dengan kombinasi pendekatan kualitatif dan kuantitatif. Pengumpulan data kualitatif dilakukan dengan melakukan survey lapangan ke lokasi objek wisata dan wawancara mendalam dengan pihakpihak yang terkait langsung dengan objek wisata Pantai Baron, sedangkan untuk pengumpulan data kualitatif dilakukan dengan pengisian kuesioner oleh pengunjung. Analisis yang dilakukan ialah analisis lokasi, analisis karakteristik tapak, analisis kondisi sarana dan prasarana, analisis daya Tarik, analisis persepsi dan preferensi, dan analisis biaya dan strategi pengelolaan sehingga dapat menghasilkan berupa faktor-faktor apa saja yang mempengaruhi pengelolaan baik dalam sarana maupun prasarana dan memberikan strategi baik dalam rencana maupun biaya untuk pantai baron.
\end{abstract}

Kata Kunci : Objek Wisata; Daya Tarik; Pengelolaan; Pantai Baron

\begin{abstract}
The government plans to create an ideal tourist area condition so that it can serve the various interests of the community, government visitors in an optimal arrangement and development effort with a mature, directed and integrated planning process so that it can be a reference in tourism development. One of the areas chosen to be developed is Gunung Kidul Regency. According to the Gunung Kidul Regency Regional Regulation on the RPJMD 2011-2021, Gunung Kidul Regency has several potential tourist areas, namely Baron Beach tourism. The author's purpose in making this report is to find out how the condition of the tourist attraction area is, both physical areas, facilities and infrastructure and provide management strategies for the Baron Beach tourist area to become sustainable tourism. Baron Beach is a beach that was first developed by the government of Gunung Kidul Regency with an area of 1.5 hectares, Baron Beach is known as a beach that has a large TPI and has the highest lighthouse so that visitors can enjoy the beauty of the beach. This beach is also the main destination for beach tourism when visiting Gunung Kidul Regency. This research is a descriptive study with a combination of qualitative and quantitative approaches. Qualitative data collection was carried out by conducting field surveys to tourist attraction locations and in-depth interviews with parties directly related to Baron Beach tourism objects, while qualitative data collection was carried out by filling out questionnaires by visitors. The analysis carried out is location analysis, site characteristics analysis, analysis of the condition of facilities and infrastructure, analysis of attractiveness, analysis of perceptions and preferences, and analysis of costs and management strategies so that it can produce in the form of any factors that affect the management of both facilities and infrastructure and provide strategy both in plan and cost for baron beach.
\end{abstract}

Keywords: Tourism Objects; Attractiveness; Management; Baron's Beach 


\section{PENDAHULUAN}

\section{Latar Belakang}

Pantai Baron adalah pantai yang dikembangkan pertamakali oleh pemerintah Kabupaten GunungKidul. Pantai ini juga menjadi tujuan utama wisata pantai jika berkunjung ke Kabupaten GunungKidul. Pantai Baron merupakan pantai yang terletak paling barat di antar pantai-pantai lainnya serta sebagai pintu gerbang masuk kawasan obyek wisata pantai di kawasan Kabupaten GunungKidul. Dalam Rencana Induk Pembangunan Kepariwisataan Provinsi DIY 2012-2025, kawasan pantai Baron dikembangkan sebagai destinasi wisata rekreasi keluarga, pendidikan, dan kuliner hasil laut. dalam Rencana Induk dan Detail Kawasan Strategis Pariwisata Nasional Karst GunungKidul dan Sekitarnya, pantai Baron dikembangkan sebagai kawasan wisata pantai berbasis pendaratan ikan, kuliner hasil laut dan wisata keluarga, dengan pengembangan desa Kemadang sebagai desa wisata untuk menikmati keindahan pantai.

Pantai Baron merupakan Pantai Selatan yang memiliki pasir putih dan bukit-bukit di sekitar pantainya. Selain melihat keindahan pantainya wisatawan juga dapat melihat aktivitas nelayan, hal ini berkaitan dengan Rencana Induk dan Detail Kawasan Strategis Pariwisata Nasional Karst GunungKidul dan Sekitarnya, Pantai Baron dikembangkan sebagai kawasan wisata pantai berbasis pendaratan ikan, dan kuliner hasil laut. Wisatawan juga dapat langsung membeli hasil tangkapannya di Tempat Pelelangan Ikan (TPI) yang terdapat di sana serta dapat membeli hasil laut tersebut yang sudah diolah di tempat makan yang ada di Ruang Terbuka Publik Tepi Pantai Baron.

Pantai Baron memiliki daya Tarik yang tidak dimiliki oleh pantai-pantai lain disekitarnya, yaitu Jika dilihat dari mercusuar yang ada di pantai baron dengan ketinggian \pm 7 meter pantai ini berbentuk huruf " $U$ " yang di kelilingi oleh bukit-bukit indah. Selain itu pantai baron juga memiliki 2 jenis air yaitu air asin dan air tawar setiap 5 tahun sekali aliran sungai bisa berubah arah aliran dengan sendirinya yang sebelumnya mengalir kea rah barat menuju laut menjadi kearah timur dan dapat memblah pasir pantai seelum mengalir ke laut. Pertemuan antara kedua aliran sungai tersebut menjadi daya tarik wisatawan untuk berkunjung ke Pantai Baron karena penasaran untuk melihat fenomana tersebut. aliran air tawar yang berasal dari bawah laut berwarna kehijauan dan aliran air laut berwarna kebiruan. Saat aliran tersebut tergabung dan membuat warna yang memikat hati, wisatawan pasti akan betah melihat kedua aliran itu.

Pantai Baron memiliki ombak yang cukup besar sehingga tak jarang terdapat wisatawan yang tidak dapat bermain air di pantainya, tetapi karena Pantai Baron memiliki keunikan yaitu terdapat teluk yang berasal dari sungai yang ada di bawah tanah sehingga wisatawan yang tidak dapat menikmati/bermain air di pantai dapat bermain air di teluk yang ombaknya tidak terlalu besar. Pantai Baron merupakan salah satu objek wisata yang cocok untuk di kunjungi baik bersama keluarga, teman, maupun rombongan sekolah. Karena selain dapat menikmati pemandangan alamnya di Kawasan Baron juga terdapat fasilitas baru yang menjadi complementer yaitu Baron Technopark sebagai kawasan pelatihan dan penelitian energy alternative PLTH (Pembangkit Listrik Tenaga Hibrida) dapat menghasilkan listrik yang dibangkitkan oleh energi dari sinar matahari, angin, dan mesin disel.

\section{Rumusan Permasalahan}

Objek Wisata Pantai Baron yang dijadikan daya Tarik utama yaitu Pantainya sendiri, Pendaratan Ikan dan Wisata Kulinernya. Namun, belum adanya rencana pengelolaan yang terstruktur. Karena Pantai Baron masih berpotendi untuk dikembangkan dan dikelola dengan lebih optimal sehingga dapat menjadi wisata berkelanjutan utuk Kabupaten GunungKidul.

\section{Tujuan}


(1) Mengetahui bagaimana kondisi kawasan objek wisata baik fisik kawasan, sarana maupun prasarana dan mengetahui apa yang dibutuhkan pengunjung agar dapat meningkatkan kualitas dan menjadi kunjungan utama saat berwisata di Kabupaten Gunungkidul; (2) Memberikan strategi pengelolaan terhadapat kawasan wisata Pantai Baron agar menjadi wisata yang berkelanjutan dan dapat meningkatkan ekonomi masyarakat sekitar.

\section{KAJIAN LITERATUR}

\section{Pariwisata}

Secara etimologi, kata pariwisata berasal dari bahasa Sansekerta yang terdiri atas dua kata yaitu pari dan wisata. Pari berarti "banyak" atau "berkeliling", sedangkan wisata berarti "pergi" atau "bepergian". Atas dasar itu, maka kata pariwisata seharusnya diartikan sebagai perjalanan yang dilakukan berkali-kali atau berputar-putar, dari suatu tempat ke tempat lain, yang dalam bahasa Inggris disebut dengan kata "tour", sedangkan untuk pengertian jamak, kata "Kepariwisataan" dapat digunakan kata "tourisme" atau "tourism" (Yoeti, 1996:112).

\section{Komponen 4A}

(1) Atraksi (atraction) Atraksi merupakan komponen yang signifikan dalam menarik wisatawan. Ada banyak alasan mengapa orang berwisata ke suatu daerah. Beberapa yang paling umum adalah untuk melihat keseharian penduduk setempat, menikmati keindahan alam, menyaksikan budaya yang unik, atau mempelajari sejarah daerah tersebut. Intinya, wisatawan datang untuk menikmati hal-hal yang tidak dapat mereka temukan dalam kehidupan mereka sehari-hari; (2) Fasilitas (Aminitis) ialah sarana dan prasarana yang dibutuhkan oleh wisatawan selama berkunjung sesuatu objek wisata ; (3) Aksesbilitas (Acces) merupakan jalan menuju transportasi umum yang dapat mempermudah wisatawan untuk berpergian kemanapun ; (4) Pelayanan Tambahan (ancillary service) merupakan sebuah pelengkap yang disediakan oleh pemerintah daerah setempat untuk tujuan wisata.

\section{Strategi Pengelolaan}

Menurut Jones (J. Winardi, 2003:106), Strategi ialah suatu kelompok keputusan, tentang tujuan apa yang akan diupayakan pencapaiannya, tindakan-tindakan yang diperlukan dan bagaimana memanfaatkan sumber-sumber dayaguna mencapai tujuan tersebut.

\section{Pengelolaan Wisata}

Menurut Muntasib (2010) pengertian pada tata kelola pariwisata adalah mekanisme pengelolaan kolaboratif pariwisata yang melibatkan sektor pariwisata dan non pemerintah dalam suatu usaha kolektif.

\section{Pengelolaan Pantai}

Menurut Undang-Undang Republik Indonesia Nomor 27 Thun 2007 mengenai Pengelolaan Wilayah Pesisir dan Pulau-Pulau Kecil. Pada UU ini berisikan Pemanfaatan dan pengusahaan perairan pesisir dan "pulau-pulau kecil dilaksanakan melalui pemberian izin pemanfaatan dan Hak Pengusahaan Perairan Pesisir (HP-3). Izin pemanfaatan diberikan sesuai dengan peraturan perundang-undangan dan kewenangan masing- masing instansi terkait". Sumberdaya pesisir yang kaya di Indonesia sering menjadi pusat pertumbuhan ekonomi / devisa negara dan ekonomi masyarakat sekitar. Wilayah pesisir dan pulau kecil rentan terhadap perubahan sehingga perlu adanya perlindungan pengelolaan agar dapat dimanfaatkan untuk memenuhi kebutuhan hidup dan penghidupan masyarakat sekitar (Coastal Management Plans).

\section{Daya Tarik}

Daya Tarik Wisata dalam buku Pengantar Ilmu Pariwisata (1985) yang di tulis oleh A Yoeti, segala sesuatu yang menjadi daya Tarik bagi pengunjung ke suatu tempat wisata dibagi menjadi 
beberapa syarat yaitu ; (1) Something to see, yaitu adanya kegiatan wisata atau atraksi wisata yang berbeda dengan objek wisata lain. Kemudian harus memiliki atraksi wisata yang dapat dijadikan entertainments jika orang berkunjung ke sana ; (2) Something to do, yaitu disediakannya fasilitas rekreasi dan tempat atau wahana yang dapat digunakan pengunjung untuk beraktivitas seperti outbound, kesenian maupun kegiatan lainnya agar membuat pengunjung betah untuk tinggal lebih lama ; (3) Something to buy, yaitu tersedia fasilitas untuk berbelanja (shopping), terutama barang-barang souvenir dan kerajinan sebagai cendramata atau oleh-oleh. Fasilitas untuk berbelanja ini tidak hanya menyediakan barang-barang yang dapat dibeli, tetapi tersedianya sarana-sarana pembantu lain untuk lebih memperlancar seperti money changer, bank, kantor pos, dan lain-lain.

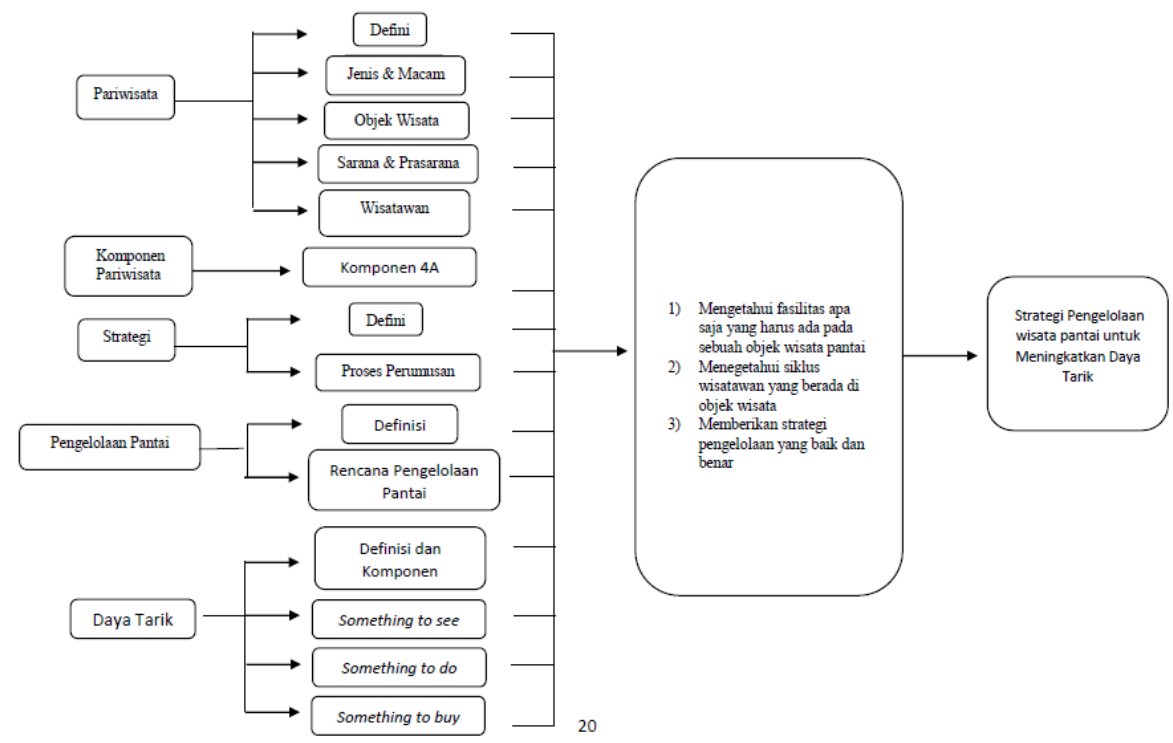

Gambar 1. Kerangka Teori

Sumber : Hasil Olahan Penulis, 2020

\section{METODE PENELITIAN}

Metode yang digunakan dalam penelitian terkait rencana pengelolaan partisipatif pada Kawasan Wisata Pantai Gunungkidul dengan menggunakan tahap-tahap yang diatur mengunakan metode analisis serta alat analisis yang tepat, sehingga tujuan bab ini dibahas untuk merencanakan pengelolaan secara partisipatif yang dilakukan stakeholder yang berkaitan dengan Kawasan Wisata Pantai Baron.

Lokasi Penelitian ini dilakukan di Kawasan Objek Wisata Pantai Baron, Desa Kemadang Kabupaten Gunung Kidul. Provinsi Daerah Istimewa Yogjakarta. Dengan luas objek wisata $\pm 1,5 \mathrm{Ha}$. batasan objek wisata Pantai Baron, adalah ; (1) Arah Barat : Untuk arah barat terdapat hutan ; (2) Arah Selatan : Untuk arah selatan terdapat objek wisata Pantai Baron yang terbentang luas ; (3) Arah Utara : Pada arah utara terdapat beberapa fasilitas yang tersedia di objek wisata Pantai Baron; (4) Arah Timur : Pada arah timur Pantai Baron berbatasan dengan Pantai Kukup. 


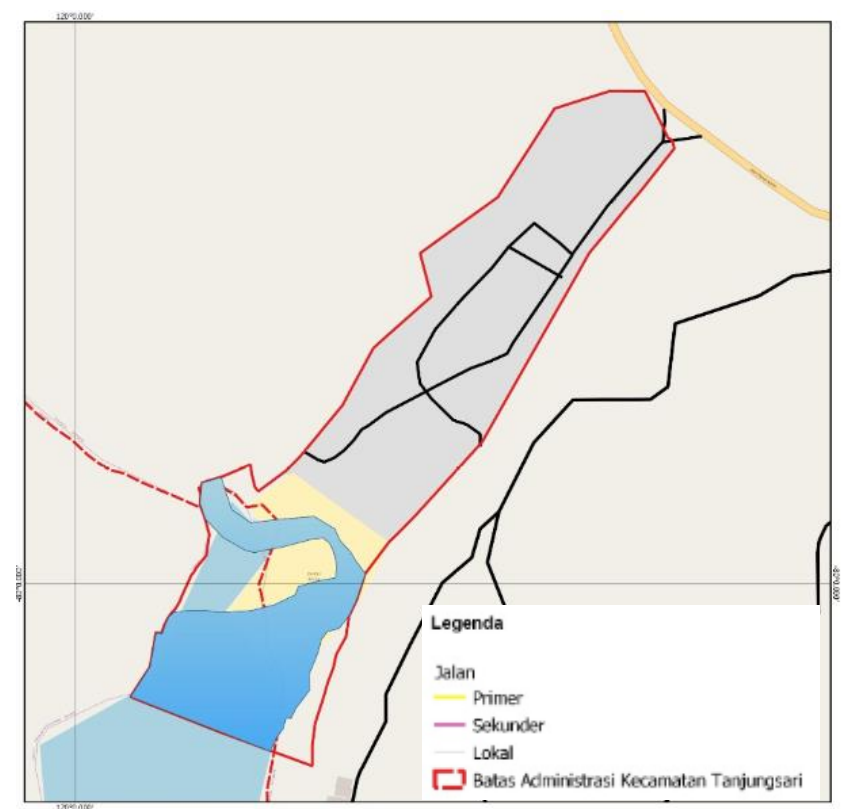

Gambar 2. Batas Deliniasi Objek Wisata Pantai Baron Sumber : Hasil Olahan Penulis melalui Qgis, 2020

Teknik pengumpulan data pada penelitian kualitatif dilakukan dengan cara berupa: a) Observasi Lapangan, b) In-depht Interview, c) Kuesioner dan d) Dokumentasi. Dalam menentukkan informan, penulis menggunakan metode purposive sampling untuk mendapatkan informan/narasumber. Informan yang ada pada penelitian, meliputi: (1) Pak Partono sebagai Ketua Dinas Pariwisata Kabupaten Gunungkidul; (2) Pak Nanang sebagai sekretaris Dinas Pariwisata Kabupaten Gunungkidul; (3) Pak Suarji sebagai kepala pokdarwis Kabupaten Gunungkidul; (4) Pak Ngatijo sebagai Sekretaris Pokdarwis Pantai Baron; (5) Ibu Silawih sebagai Pedagang Warung Makanan; (6) Pak Risky sebagai driver damri di Pantai Baron.

\section{DISKUSI DAN HASIL}

\section{Analisis Lokasi}

Pada analisis lokasi ini membahas mengenai aksesibiltas dan proximity antara objek wisata dengan tempat tujuan lain, baik tempat wisata maupun lokasi-lokasi kota dan transportasi umum. Untuk aksesibilitas dari objek lahan menuju kota dan transportasi umum sekitar 50-100 $\mathrm{km}$ dengan waktu tempuh $\pm 1,5-2,5 \mathrm{jam}$. Tetapi untuk wisata pantai dapat di tempuh dengan waktu beberapa menit saja karena Kabupaten Gunungkidul adalah pantai panjang selatan yang Pantai Baron merupakan gerbang pintu masuk ke pantai-pantai yang ada di Kabupaten Gunungkidul, selain pantainya pada Kabupaten Gunungkidul terdapat wisata lain seperti Gua, Wahana bermain dan berfoto, Wisata Kuliner dan masih banyak lainnya. dari hasil survey secara langsung untuk kondisi jalan menuju objek wisata dapat di katakana baik hanya saja terdapat beberapa kekurangan yaitu, kurangnya pencahayaan dan jalan yang curam tanpa adanya batas hal ini di karenakan lokasi objek wisata yang berada di pegunungan sehingga jalan cukup curam dan banyak belokan tajam.

\section{Analisis Karakteristik Tapak}

Tapak pada objek lahan memiliki bentuk fisik memanjang dari pantai hingga pintu masuk dengan luas sebasar $\pm 1,5 \mathrm{Ha}$. jika dilihat dari topografinya Pantai Baron memiliki kemiringan lereng datar bergelombang hal ini membuat morfologi memiliki dinamika yang cukup tinggi, keberadaan sungai kecil/muara sungai sangat berpengaruh yang cukup kuat karena memiliki karakteristik yang mempengaruhi ombak sehingga membuat Pantai Baron sangat mudah tererai walau hanya dengan tenaga yang lebih kecil dibandingkan Pantai lainnya. di sekitar Pantai Baron masih 
didominasi hutan yang ditumbuhi berbagai jenis tanaan dari beberapa family yang berbeda.

Tabel 1. Parameter Tapak Objek Wisata Pantai Baron

\begin{tabular}{clc}
\hline No & \multicolumn{1}{c}{ Parameter } & Pantai Baron \\
\hline $\mathbf{1}$ & Sudut Kelerengan Gisik Pantai & 4.86 \\
\hline $\mathbf{2}$ & Kemiringan Pantai (Derajat) & $80-90$ \\
\hline $\mathbf{3}$ & Tinggi Gelombang (m) & 1.321 \\
\hline $\mathbf{4}$ & Periode Gelombang (s) & 12.978 \\
\hline $\mathbf{5}$ & Arah Angin & $80 \mathrm{NE}$ \\
\hline $\mathbf{6}$ & Kecepatan Angin (Knot) & $5-16$ \\
\hline $\mathbf{7}$ & Kedalaman air laut di pantai (m) & 0.36 \\
\hline $\mathbf{8}$ & Jarak bts pantai ke pasang tertinggi (r dalam m) & 61.67 \\
\hline $\mathbf{9}$ & Diameter Pasir & 0.515 \\
\hline $\mathbf{1 0}$ & Skala Wenthworth & Medium \\
\hline $\mathbf{1 1}$ & Jangkauan Pasang Surut (m) & 61.445 \\
\hline $\mathbf{1 2}$ & Energi Gelombang (joule) & 2193 \\
\hline $\mathbf{1 3}$ & Indeks Hempasan Gelombang (K) & 0.009 \\
\hline $\mathbf{1 4}$ & Jenis Gelombang & Pluging \\
\hline $\mathbf{1 5}$ & Faktor Penentu Akresi & 5.903
\end{tabular}

Sumber : MasterPlan Kawasan Baron, 2019

\section{Analisis Kondisi Sarana dan Prasarana}

Dari hasil survey lapangan secara langsung baik kondisi sarana maupun prasarana dapat dikatakan cukup baik hanya saja ada beberapa kios dan los yang tutup dikarenakan pandemic yang sedang terjadi sehingga terlihat kurang terurus pada bagian kios dan los yang berada di bagian dalam. Untuk sarana dan prasarana yang ada di pantai baron menurut hasil survey dan data yang telah di dapat di bawah ini adalah kondisi dan jumlah sarana yang ada di objek wisata.

Tabel 2. Jumlah dan Kondisi Sarana yang Tersedia di Pantai Baron

$\begin{array}{lcccc}\text { NO } & \text { SARANA } & \text { BENTUK } & \text { STATUS } & \text { KONDISI } \\ & \text { BANGUNAN } & \text { JUMLAH } & \text { KEPMILIKAN } & \end{array}$

\begin{tabular}{|c|c|c|c|c|c|}
\hline 1 & Peribadatan & Masjid & 1 & Umum & $\begin{array}{l}\text { Kondisi cukup baik hanya saja karena bangunan } \\
\text { sudah cukup tua terdapat beberapa bangunan } \\
\text { yang sudah cuckup lapuk dan pada saat saya } \\
\text { survey (masa pandemic) sarana peribadatan di } \\
\text { tutup sehingga pengunjung hanya dapat } \\
\text { mengunakan tempat peribadatan bagian luar } \\
\text { saja. }\end{array}$ \\
\hline \multirow{2}{*}{2} & \multirow{2}{*}{ Akomondasi } & Los & 55 & Pemda & \multirow{2}{*}{$\begin{array}{c}\text { Kondisi cukup baik untuk beberapa kios dan los } \\
\text { yang di tempati, karena penulis melakukan } \\
\text { survey di saat pandenic ada beberapa kos dan } \\
\text { los yang tidak di tempatin sehingga terlihat } \\
\text { tidak terurus. }\end{array}$} \\
\hline & & Kios & 33 & Pemda & \\
\hline
\end{tabular}




$\begin{array}{cccc}\text { NO } & \text { SARANA } & \text { BENTUK } & \text { STATUS } \\ \text { BANGUNAN } & \text { JUMLAH } & \text { KEPMILIKAN }\end{array}$

KONDISI

$\begin{array}{ll}\text { Kamar } & \text { Kamar } \\ \text { Mandi } & \text { Mandi }\end{array}$

14

Pemda

Kamar mandi di objek wisata Pantai Baron dibagi menjadi 2 pengurusan yaitu pemda dan masyarakat. Pada kamar mandi terlihat perbedaan kondisi, pada kondisi kamar mandi pemda terlihat terurus dan memiliki lantai keramik sedangkan kamar mandi yang di bawah pengurusan masyarakat juga dalam kondisi baik tetapi lantainya tidak dari keramik dan berada di luar atau tidak didalam sebuah bangunan.

$26 \quad$ Masyarakat

penginapan yang ada di sekitar objek wisata Pantai Baron tidak terlalu banyak hanya ada penginapan seperti tempat makan menyediakan kamar kosong yang tidak terpakai dan di sewakan. Harga sewa permalam sekitar Rp 150.000 - R p 250.000 dengan fasilitas yang cukup lengkap seperti kamar mandi dalam, ac, tv, kasur, lemari dan tempat berkumpul

\begin{tabular}{|c|c|c|c|c|c|}
\hline 5 & Parkiran & $\begin{array}{c}\text { Tempat } \\
\text { parkir }\end{array}$ & 3 & Pemda & $\begin{array}{l}\text { parkiran yang ada di objek lahan cukup besar } \\
\text { dan dapat menampung kurang lebih } 250 \text { - } 300 \\
\text { kendaraan baik mobil, motor dan bus }\end{array}$ \\
\hline 6 & TPI & $\begin{array}{l}\text { Tempat } \\
\text { pelelangan } \\
\text { ikan }\end{array}$ & 1 & Pemda & $\begin{array}{l}\text { kondisi tpi cukup baik dan cukup besar sehingga } \\
\text { dapat menampung hasil penangkapan ikan yang } \\
\text { di tangkap oleh nelayan }\end{array}$ \\
\hline 7 & Kesehatan & Puskesmas & 1 & Pemda & $\begin{array}{c}\text { untuk tempat kesehatan memiliki bangunan } \\
\text { yang cukup besar dan memiliki } 1 \text { mobil } \\
\text { ambulace yang siap sedia jika terjadi kecelakaan }\end{array}$ \\
\hline 8 & Informasi & TIS & 1 & Pemda & $\begin{array}{c}\text { untuk sarana informasi yang ada di objek wisata } \\
\text { memiliki kondisi yaang cukup karena sarana } \\
\text { informasi ini tidak memiliki bentuk bangunan } \\
\text { hanya terdapat tenda yang di jaga oleh } \\
\text { beberapa orang. }\end{array}$ \\
\hline 9 & Panggung & & 1 & Pemda & $\begin{array}{l}\text { panggung yang berada di tengah objek wisata } \\
\text { Pantai Baron ini memiliki kondisi yang cukup } \\
\text { baik tetapi karna bangunan ini sudah cukup } \\
\text { lama sehingga ada beberapa bagian yang sudah } \\
\text { tidak baik seperti kondisi awal }\end{array}$ \\
\hline 10 & $\begin{array}{c}\text { Gardu } \\
\text { Pandang }\end{array}$ & & 1 & Pemda & $\begin{array}{l}\text { kondisi gardu pandang cukup baik dan cukup } \\
\text { aman untuk pengunjung datangi, karena gardu } \\
\text { pandang di objek wisata menjadi salah satu } \\
\text { atraki yang sangat di gemari pengunjung. }\end{array}$ \\
\hline
\end{tabular}


Tabel 3. Komponen dan Aspek Komponen Prasarana di Pantai Baron

\begin{tabular}{|c|c|c|}
\hline \multicolumn{3}{|c|}{ Prasarana } \\
\hline Komponen & Aspek dari Komponen & Keterangan \\
\hline \multirow{2}{*}{$\begin{array}{c}\text { Jalan menuju laut untuk evakuasi } \\
\text { dan jalaur angkutan barang untuk } \\
\text { nelayan }\end{array}$} & Panjang: 507 m;lebar jalan: 3 m & Latak pada sisi Barat \\
\hline & Panjang: $551 \mathrm{~m}$;lebar jalan: 5 m & Letak pada sisi Timur \\
\hline Luas Area berkumpul & 282 m2, 198m2 (dekat punden) & Letak di tengah area kuliner \\
\hline Area evakuasi di bukit karts & $\begin{array}{c}\text { Terdapat } 3 \text { jalur evakuasi menuju } \\
\text { atas bukit }\end{array}$ & $\begin{array}{l}\text { Letak di bukit karst sisi } \\
\text { Timur Kawasan }\end{array}$ \\
\hline $\begin{array}{c}\text { Jalur untuk pejalan kaki dilereng } \\
\text { bukit karst untuk fasilitas jelajah } \\
\text { bukit karst }\end{array}$ & Panjang: 400 m; Lebar: 2 m & Letak di sisi Timur kawasan \\
\hline IPAL & $\begin{array}{c}\text { Ukuran: lebar } 5 \text { memang diatas } \\
\text { jalan bagian timur sepanjang } 33 \\
\mathrm{~m}\end{array}$ & Letak di sisi timur depan TPI \\
\hline Jaringan air limbah & $\begin{array}{l}\text { Di buang ke laut setelah melalui } \\
\text { pengolahan pada IPAL. }\end{array}$ & $\begin{array}{c}\text { Terdapat dua jalur sisi Barat } \\
\text { dan Timur Kawasan dan } \\
\text { berujung pada IPAL di sisi } \\
\text { Timur kawasan. }\end{array}$ \\
\hline
\end{tabular}

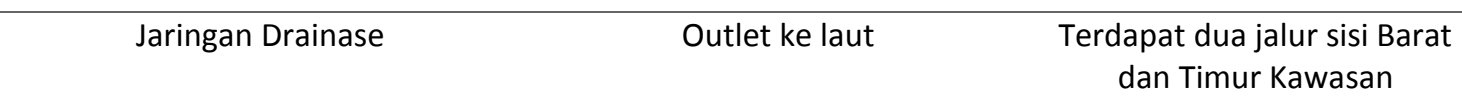

Sumber : MasterPlan Kawasan Baron, 2019

\section{Analisis Daya Tarik}

- Something to see yaitu adanya kegiatan wisata atau atraksi wisata yang berbeda dengan objek wisata lain atau memiliki daya Tarik khusus. Objek wisata Pantai Baron Pantai Baron memiliki daya Tarik yang tidak dimiliki oleh pantai-pantai lain disekitarnya, yaitu Jika dilihat dari mercusuar yang ada di pantai baron dengan ketinggian \pm 7 meter pantai ini berbentuk huruf " $U$ " yang di kelilingi oleh bukit-bukit indah. Selain itu pantai baron juga memiliki 2 jenis air yaitu air asin dan air tawar setiap 5 tahun sekali aliran sungai bisa berubah arah aliran dengan sendirinya yang sebelumnya mengalir kea rah barat menuju laut menjadi kearah timur dan dapat memblah pasir pantai seelum mengalir ke laut. Pertemuan antara kedua aliran sungai tersebut menjadi daya tarik wisatawan untuk berkunjung ke Pantai Baron karena penasaran untuk melihat fenomana tersebut. aliran air tawar yang berasal dari bawah laut berwarna kehijauan dan aliran air laut berwarna kebiruan. Saat aliran tersebut tergabung dan membuat warna yang memikat hati, wisatawan pasti akan betah melihat kedua aliran itu. Hal ini merupakan salah satu faktor yang membantu dalam pemasaran atau promosi pada objek wisata Pantai Baron menjual keindahan alam dan pemandangannya. 
- Something to do berarti di objek wisata tersebut terdapat banyak yang dilihat dan disakikan. Setiap objek wisata wajib menyediakan fasilitas atraksi dan rekreasi yang dapat digunakan pengunjung untuk melakukan aktivitas setiap melakukan kunjungan ke objek wisata seperti olahrga, berbelanja, kesenian, maupun kegiatan lain yang membuat pengunjung betah dan balik lagi ke objek wisata. Dengan kondisi alam yang ada, fasilitas lain yang tersedia yaitu melihat pemandangan dari mercusuar, bermain perahu dengan perahu nelayan, memancing, beberapa spot untuk berfoto dan duduk santai di pinggir pantai dan melihat pemandangan pantai yang indah dengan beberapa bukit di sekitar pinggir pantai.

- Something to buy adalah sebuah objek wisata harus menyiadakan atau terdapat fasilitas untuk berbelanja, baik barang souvenir, kerjaninana, atau oleh-oleh yang di buat masyarakat sekitar untuk dibwa pulang ke tempat asal pengunjung. Pada objek wisata Pantai Baron memiliki banyak kios dan los yang menjual beberapa oleh-oleh khas Kabupaten Yogjakarta, seperti kerajinan yang terbuat kerang (tas, rombe-rombe, pajangan, pin, dII). selain dapat membeli kerjainan di Pantai Baron Juga di kenal dengan pasar buah yang menjual beberapa buah yang jarang di temui di tempat lain, seperti buah srikaya yang rasanya sangat manis dan sangat banyak di pasar pantai baron dan menjaul beberapa sefood yang bisa di bawa pulang dan banyak terdapat di Yogjakarta tetapi jarang di tempat lain, yaitu undur-undur.

\section{Analisis Persepsi dan Referensi Pengunjung}

Analisis persepsi dilakukan dengan menggunakan metode IPA (Importance Performance Analysis) dan CSI (Customer Satisfaction Index) yang dihitung dengan skala likert dari hasil penyebaran kuesioner pengunjung. Dari hasil perhitungan CSI didapatkan hasil nilai kepuasan pengunjung sebesar $62,53 \%$, yang dapat disimpulkan bahwa pengunjung merasa cukup puas terhadap fasilitas yang disediakan objek wisata Pantai Baron.

Untuk hasil analisis referensi di dapatkan pengunjung memiliki keinginan untuk objek lahan menambahkan wahana baru atau atraksi untuk meningkatkan dan mendukung atriksi utama yaitu pantainya sendiri. Dari hasil yang di dapatkan dari 100 responden mengahasilkan seperti tabel di bawah ini

Tabel 4. Kegiatan Wisata Baru yang Perlu Diadakan

\begin{tabular}{|c|c|c|}
\hline Jenis Kegitan Wisata & Skor & Peringkat \\
\hline Spot foto & 8 & 4 \\
\hline Penodpo & 11 & 2 \\
\hline Penataan dan Pengelolaan yang lebih baik & 10 & 3 \\
\hline Permainan & 42 & 1 \\
\hline Surfing & 1 & 7 \\
\hline Tempat Edukasi & 7 & 5 \\
\hline Jembatan yang lebih menarik & 6 & 6 \\
\hline Wisata Ramah Lansia & 8 & 4 \\
\hline Taman & 7 & 5 \\
\hline
\end{tabular}

Sumber : Hasil Olahan Penulis, 2020

Dari hasil preferensi pengunjung juga di dapatkan hal apa saja yang menjadi kendala selama pengunjung mengunjungi objek wisata Pantai Baron, yaitu : 
Tabel 5. Kendala yang Dirasakan

\begin{tabular}{lcc}
\hline \multicolumn{1}{c}{ Kendala } & Skor & Peringkat \\
\hline Jalan Berliku dan Curam & 36 & 2 \\
\hline Tranportasi & 43 & 1 \\
\hline Kurangnya Pencahayaan & 21 & 3 \\
\hline
\end{tabular}

Sumber : Hasil Olahan Penulis, 2020

\section{Analisis Biaya}

Dari hasil kuesioner yang telah di sebar kepada 100 responden juga menghasilkan suatu biaya yang diharpkan pengunjung dapat terleksan pada objek wisata Pantai Baron kedepannya, hal yang di inginkan seperti biaya tiket masuk di tingkatkan dengan syarat adanya fasilitas tambahan yang disediakan, tiket parkir dikenakan biaya Rp 4.000 tanpa biaya tambahan, dan adanya atraksi baru yang di tambahkan. Sehingga menghasilkan angka seperti gambar di bawah ini

Gambar 3. Asumsi Pendapatan yang Dihasilkan

Sumber : Hasil Kuesioner Penulis, 2020

\begin{tabular}{|c|c|c|c|c|c|c|c|c|c|c|c|c|c|c|c|}
\hline \multicolumn{16}{|c|}{ Pendapatan } \\
\hline No & Keterangan & Asumsi & 0 & Januari & Februari & Maret & April & Mei & Juni & Juli & Agustus & September & Oktober & November & Desember \\
\hline 1 & $\begin{array}{l}\text { Tiket Masuk Rp } 15.000 \text { i orang } \\
\text { (Dengan tambahan fasilitas, } \\
\text { payung \& tiker pantail }\end{array}$ & 1.800 (penguniung) & 27.000 .000 & 27.000 .000 & 27.000 .000 & 27.000 .000 & 27.000 .000 & 27.000 .000 & 27.000 .000 & 27.000 .000 & 27.000 .000 & 27.000 .000 & 27.000 .000 & 27.000 .000 & 27.000 .000 \\
\hline & Parkir Kendaraan Rp 4.000i & & & & & & & & & & & & & & \\
\hline 2 & Kendaraan & 520 (kendaraan) & 2.080 .000 & 2.080 .000 & 2.080 .000 & 2.080 .000 & 2.080 .000 & 2.080 .000 & 2.080 .000 & 2.080 .000 & 2.080 .000 & 2.080 .000 & 2.080 .000 & 2.080 .000 & 2.080 .000 \\
\hline 3 & Nelayan & & 500.000 & 500.000 & 500.000 & 500.000 & 500.000 & 500.000 & 500.000 & 500.000 & 500.000 & 500.000 & 500.000 & 500.000 & 500.000 \\
\hline 4 & Kios $220.000(33)$ & & 7.260 .000 & 7.260 .000 & 7.260 .000 & 7.260 .000 & 7.260 .000 & 7.260 .000 & 7.260 .000 & 7.260 .000 & 7.260 .000 & 7.260 .000 & 7.260 .000 & 7.260 .000 & 7.260 .000 \\
\hline 5 & Los $100.000(55)$ & & 5.500 .000 & 5.500 .000 & 5.500 .000 & 5.500 .000 & 5.500 .000 & 5.500 .000 & 5.500 .000 & 5.500 .000 & 5.500 .000 & 5.500 .000 & 5.500 .000 & 5.500 .000 & 5.500 .000 \\
\hline 6 & Mercusuar Rp 5.000\} Orang & 350 (orang) & 1.750 .000 & 1.750 .000 & 1.750 .000 & 1.750 .000 & 1.750 .000 & 1.750 .000 & 1.750 .000 & 1.750 .000 & 1.750 .000 & 1.750 .000 & 1.750 .000 & 1.750 .000 & 1.750 .000 \\
\hline 7 & Kolam Renang Buatan Rp 8.000 & 300 (orang) & & & & 2.400 .000 & 2.400 .000 & 2.400 .000 & 2.400 .000 & 2.400 .000 & 2.400 .000 & 2.400 .000 & 2.400 .000 & 2.400 .000 & 2.400 .000 \\
\hline 8 & PerlengkapanBerenang(Papan & 150 (orang) & 1.500 .000 & 1.500 .000 & 1.500 .000 & 1.500 .000 & 1.500 .000 & 1.500 .000 & 1.500 .000 & 1.500 .000 & 1.500 .000 & 1.500 .000 & 1.500 .000 & 1.500 .000 & 1.500 .000 \\
\hline 9 & PerahuRp 10.0001 orang & 150 (orang) & & & 1.500 .000 & 1.500 .000 & 1.500 .000 & 1.500 .000 & 1.500 .000 & 1.500 .000 & 1.500 .000 & 1.500 .000 & 1.500 .000 & 1.500 .000 & 1.500 .000 \\
\hline 10 & Tempat Edukasi (20.000/orang) & 100 (orang) & & & 2.000 .000 & 2.000 .000 & 2.000 .000 & 2.000 .000 & 2.000 .000 & 2.000 .000 & 2.000 .000 & 2.000 .000 & 2.000 .000 & 2.000 .000 & 2.000 .000 \\
\hline \multirow{2}{*}{\multicolumn{3}{|c|}{$\begin{array}{l}\text { Pendapatan Perbulan } \\
\text { Pendapatan Pertahun }\end{array}$}} & 45.590 .000 & 45.590 .000 & 49.090 .000 & 51.490 .000 & 51.490 .000 & $\begin{array}{l}51.490 .000 \\
\end{array}$ & \begin{tabular}{|l|}
51.490 .000 \\
\end{tabular} & \begin{tabular}{|l|}
51.490 .000 \\
\end{tabular} & 51.490 .000 & 51.490 .000 & 51.490 .000 & 51.490 .000 & 51.490 .000 \\
\hline & & & 655.170 .000 & & & & & & & & & & & & \\
\hline
\end{tabular}

Gambar 4. Asumsi Pengeluaran yang Dihasilkan

Sumber : Hasil Kuesioner Penulis, 2020

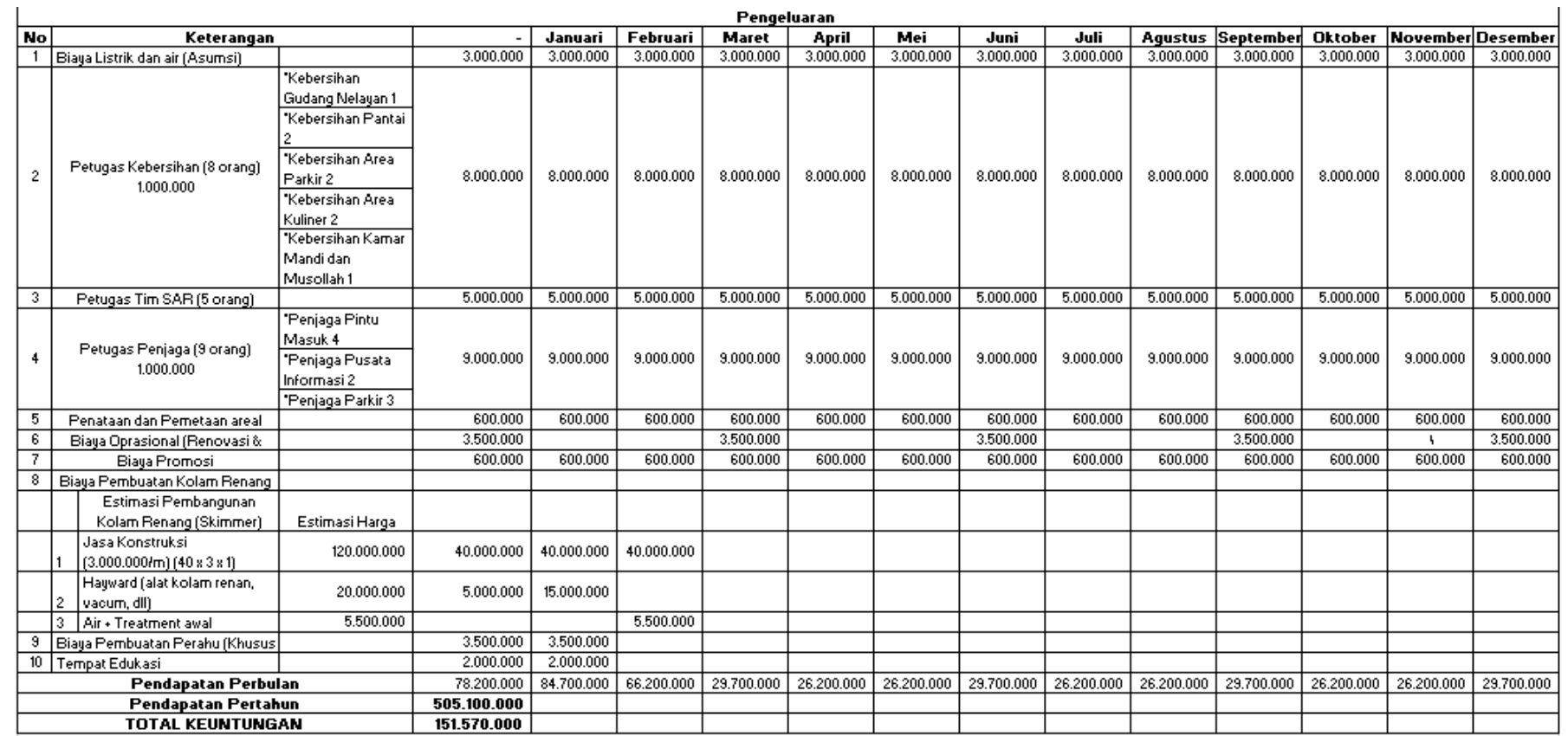




\section{KESIMPULAN, REKOMENDASI DAN SARAN Kesimpulan}

Dalam Rencana Induk Pembangunan Kepariwisataan Provinsi DIY 2012-2025, kawasan Baron dikembangkan sebagai destinasi wisata rekreasi keluarga, pendidikan, dan kuliner hasil laut dan Dalam Rencana Induk dan Detail Kawasan Strategis Pariwisata Nasional Karst Gunung Kidul dan Sekitarnya, pantai Baron dikembangkan sebagai kawasan wisata pantai berbasis pendaratan ikan, kuliner hasil laut dan wisata keluarga, dengan pengembangan Desa Kemadang sebagai desa wisata untuk menikmati keindahan pantai. Kondisi fisik baik sarana maupun prasarana yang ada di objek wisata Pantai Baron sudah dapat dikatakan baik hanya ada beberapa bangunan saja yang sudah tua tetapi hal itu sudah direncanakan oleh pemerintah dalam masterplan bahwa ada perbaikan bangunan yang sudah tua dan tak layak.

Dari hasil kuesioner didapatkan bahwa pengunjung menginginkan adanya kegiatan wisata baru, seperti permainana anak (kolam renang buatan, ayunan, tempat edukasi,dll), pendopo, dan spot foto. selain kegiatan baru dari hasil kuesioner juga di dapatkan kendala yang di rasakan pengunjung saat berwisata ke Objek Wisata Pantai Baron, yaitu fasilitas Transportasi, jalan yang berliku, dan pencahayaan yang kurang baik. Jika dilihat dari biaya, semua pembangunan dapat tidak menjadi penghalang pada biaya pendapatan di Pantai Baron. Selin itu Pantai Baron juga telah mendapatkan biaya bantuan BAPPEDA (Badan Perencanaan Pembangunana Daerah) sebesar 5 milyar dari dana APBG (Anggaran Pendapatan dan Belanja Gampong).

\section{Rekomendasi}

1) Memunculkan kegiatan baru seperti Kolam Renang Buatan Taman, Spot Foto Baru Membatik dan Membuat Kerajinan Tangan pajangan yang terbuat dari kerang dan merajut Karena terdapat banyak sekali kerang sehingga bisa di manfaatkan menjadi kerajinan tangan.

2) Jalan pintas menuju mercusuar dari Pantai Baron di perbaiki agar lebih mudah dan aman pengunjung melalui.

3) Melakukan promosi baik di media social maupun media cetak hal ini baik agar semakin banyak yang mengetahui mengenai Pantai Baron, selain melalui media social dan media cetak memasukan Pantai Baron ke Travel Tour juga menjadi salah satu promosi yang baik untuk perkembangan Pantai Baron.

4) Menambahkan mobil Damri dan menambahkan waktu kerjanya menambahkan lampu pada jalan menuju Objek Wisata maupun di Kawasan Pantai.

\section{Saran}

- Dinas Pariwisata (Dispar) Kabupaten Gunungkidul, sebagai salah satu badan yang menangani dalam rencana pembangunan dan perencanaan Pantai Baron sebaikanya ada perbaikan atau revitalisasi bangunan dan sarana prasarana hal ini dikarenakan selama penulis melakukan survey secara langsung terdapat beberapa bangunan yang sudah cukup tua sehingga membutuhkan perbaikan.

- Kelompok Sadar Wisata (Pokdarwis) Pantai Baron, dari hasil wawancara penulis mendapatkan informasi bahwa yang mengurus bagian parkir adalah pokdarwis. Penulis hanya ingin memberikan saran untuk petunjuk jalan menuju parkir di perbanyak, hal ini di karenakan hanya ada 2 petunjuk jalan menuju parkir di bagian depan saja ssedangkan parkir yang ada di pantai baron cukup luas sehingga tak jarang terlihat parkir yang berantakan walupun sudah terdapat petugas parkir.

- Masyarakat sekitar Objek Wisata Pantai Baron yang berjualan di area objek wisata. Sarannya yaitu dengan tetap menjaga lingkungan dengan baik, tidak membuang sampah sembarangan, tidak berjualan melewati batas yang telah di berikan atau batar area kuliner dan perdagangan dan membatu promosi pantai melalui makananatau barang yang mereka jual melalui media social. 


\section{REFERENSI}

Atmadjaja, S. (2003). Konsep Strategi. Konsep Strategi, 106. Environment, D. O. (2002). Coastal Management Plans. Comittees Of Management On the Coast, 1-2.

Kidul, B. P. (2017). Penyusunan Masterplan Penataan Kawasan Baron. Laporan Akhir Penyususnan Materplan Penataan Kawasan Baron , 1-109.

Muntasib. (2010). Tata Kelola Pariwisata. Pariwisata .

Undang-Undang Republik Indonesia Nomor 27 Thun 2007 mengenai Pengelolaan Wilayah Pesisir dan Pulau-Pulau Kecil

Winardi, J. (2003). Strategi Pengelolaan. Strategi , 106.

Yoeti, O. A. (1996). Pengantar IImu Pariwisata . Bandung: Angkasa. 